Victoria McGeer

\title{
The Skill of Perceiving Persons
}

\section{SECTION 1: PERCEIVING PERSONS}

What is it that we ordinarily perceive when we perceive a person? The behaviourist might claim we see a body, apparently self-propelled, interacting in various complex ways with its surrounding environment. If we are daring (or naïve), we might go beyond these observable features of body, inferring - as some might say - the presence of something like an animating agency or personality, a seat of sensation, emotion and reasoning akin to what we experience in our own case. How daring are these so-called inferences? To some philosophers, they have seemed daring enough to generate a sceptical problem of other minds. To others, the problem of other minds has seemed nothing more than a philosophical pseudo-problem, rooted in a deeply misguided picture of what we actually perceive when we perceive a person.

A fresh perspective on this dispute may come from abnormal psychology. There are certain human beings for whom the problem of other minds is profoundly real. Individuals with autism seem not to perceive persons as others typically do. As one highly intelligent young man with autism observed:

"I really didn't know there were other people until I was seven years old. I then suddenly realised there were other people. But not like you do. I still have to remind myself that there are other people. I could never have a friend. I really don't know what to do with other people, really." (quoted in Hobson 1992: 165)

For typical individuals, it's hard to imagine what this kind of experience could be like. If anything, everyday encounters with other individuals have an irresistible agentive quality about them. Typical human beings are more than ready to see others as persons, discerning in their activities an animating agency constituted by a rich variety of intentional, emotional and perceptual states: beliefs, desires, hopes, fears, joys, jealousies, pains, pleasures, and a panoply of others. In fact, typical human beings are not content with perceiving other adults in this way - they readily attribute such states to infants, to family pets, to other domesticated and undomesticated creatures, even to their word processors. 
In one compelling study of this 'anthropomorphizing' proclivity, the psychologists Heider and Simmel prepared a short animated film clip consisting of nothing but geometric figures - two triangles and a circle - moving in and around a large rectangular enclosure (Heider and Simmel 1944 - see figure 1) The animation, which lasts about a minute and a half, conveys to most people who view it a heroic tale of a young Galahad protecting his small companion from the bullying attacks of an evil oppressor. Not so for high-functioning autistics who fail, by and large, to make any mentalistic attributions at all — and even among those who do make such attributions, they fail to weave them into the sort of : sense-making narrative that characterizes the experience of a typical viewer (Klin 2000). Two sample narratives collected from adolescents viewing the Heider and Simmel film will give a taste of this difference. The first is from a typically developing individual; the second from a high-functioning individual with autism of comparable verbal IQ (Klin 2000: 840):

(Typically developing adolescent) "What happened is that the larger triangle - which was like a bigger kid or bully - and he had isolated himself from everything else until two new kids come along and the little one was a bit more shy, scared, and the smaller triangle more like stood up for himself and protected the little one. The big triangle got jealous of them, came out, and started to pick on the smaller triangle. The little triangle got upset and said like, 'what's up?' "Why are you doing this?" (adolescent with autism) "The big triangle went into the rectangle. There was a small triangle and a circle. The big triangle went out. The shapes bounce off each other. The small circle went inside the rectangle. The big triangle was in the box with the circle. The small triangle and the circle went around each other a few times. They were kind of oscillating around each other, maybe because of a magnetic field. After that, they go off the screen. The big triangle turned like a star - like a star of david - and broke the rectangle."

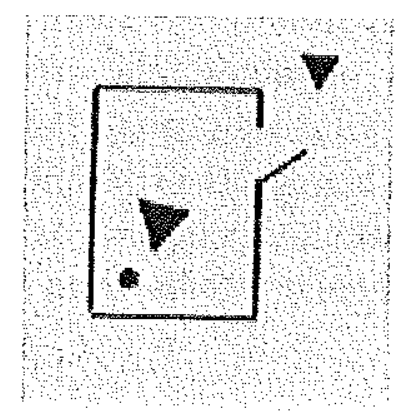

Figure 1. Still image from Heider and Simmel (1944) film clip 
The contrast between typical and autistic human beings is clear: Typical human beings are not only active mentalizers: they are inveterate metalizers - a fact that has a profound effect on the nature and quality of their interactions. From the autistic perpective, such interactions seem nothing short of miraculous. This is nicely captured by Oliver Sacks, describing the (self-reported) childhood experience of Temple Grandin, a remarkably gifted individual with autism:

Something was going on between the other kids, something swift, subtle, constantly changing - an exchange of meanings, a negotiation, a swiftness of understanding so remarkable that sometimes she [Grandin] wondered if they were all telepathic. She is now aware of the existence of these social signals. She can infer them, she says, but she herself cannot perceive them, cannot participate in this magical communication directly, or conceive the many-levelled kaleidoscopic states of mind behind it. Knowing this intellectually, she does her best to compensate, bringing immense intellectual effort and computational power to bear on matters that others understand with unthinking ease. This is why she often feels excluded, an alien (Sacks 1995: 272)

A natural explanation for this continuing alien experience is expressed in these observations: Grandin, and other autistic individuals (if they are lucky), come to know about other minds by genuine inference, working to understand the kind of complex psychological states others have based on observing their behaviour. Typical human beings, by contrast, have a different kind of access to other minds - something very like direct perception. As the psychologist Alison Gopnik remarks:

... our perception of mental states in others is, at least much of the time, no less immediate than our perception of our own mental states. I 'see' my son's hunger or my friend's disappointment just as directly as I see my own. Indeed, if we imagine what a purely physical perception of other people would be like, a perception from which we then inferred their mental states, it seems as bizarre as imagining ordinary visual perception as an inference from an uninterpreted pattern of light and dark. Imagine seeing the other people around you at the dinner table, say, as bags of skin stuffed into bags of cloth, with two small restless black spots near the top and a hole underneath that emits noises. This is a mad view. At the most immediate 


























